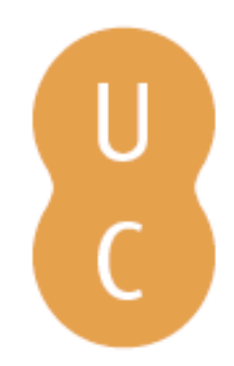

\title{
nombalina
}

\section{Uma análise comparativa entre o método GNSS de PPP e os métodos geodésicos convencionais}
Autor(es):
Arnaut, Adriana Andrade; Santos, Antonio José Prado Martins; Santos, Christian Pereira Lopes dos

Publicado por: Imprensa da Universidade de Coimbra

URL persistente:

URI:http://hdl.handle.net/10316.2/37082

DOI:

DOI:http://dx.doi.org/10.14195/978-989-26-0983-6_29

Accessed : $\quad$ 26-Apr-2023 11:55:01

A navegação consulta e descarregamento dos títulos inseridos nas Bibliotecas Digitais UC Digitalis, UC Pombalina e UC Impactum, pressupõem a aceitação plena e sem reservas dos Termos e Condições de Uso destas Bibliotecas Digitais, disponíveis em https://digitalis.uc.pt/pt-pt/termos.

Conforme exposto nos referidos Termos e Condições de Uso, o descarregamento de títulos de acesso restrito requer uma licença válida de autorização devendo o utilizador aceder ao(s) documento(s) a partir de um endereço de IP da instituição detentora da supramencionada licença.

Ao utilizador é apenas permitido o descarregamento para uso pessoal, pelo que o emprego do(s) título(s) descarregado(s) para outro fim, designadamente comercial, carece de autorização do respetivo autor ou editor da obra.

Na medida em que todas as obras da UC Digitalis se encontram protegidas pelo Código do Direito de Autor e Direitos Conexos e demais legislação aplicável, toda a cópia, parcial ou total, deste documento, nos casos em que é legalmente admitida, deverá conter ou fazer-se acompanhar por este aviso.

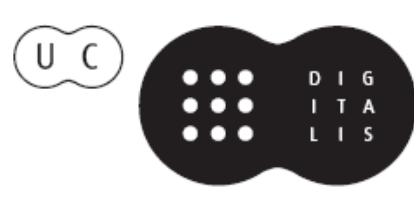




\section{$\forall$ \\ TAS DAS I JORNADAS LUSÓFONAS DE CIÊNCIAS E TECNOLOGIAS DE INFORMAÇÃO GEOGRÁFICA}

Editores

José Gomes dos Santos

Cidália Fonte

Rui Ferreira de Figueiredo

Alberto Cardoso

Gil Gonçalves

José Paulo Almeida

Sara Baptista 


\title{
A RTIG O 29 \\ UMA ANÁlise COMPARATIVA ENTRE O MÉTODO GNSS DE PPP E OS MÉTODOS GEODÉSICOS CONVENCIONAIS
}

\author{
ARNAUT, Adriana Andrade ${ }^{1}$; SANTOS, Antonio José Prado Martins ${ }^{2}$ \\ E SANTOS, Christian Pereira Lopes dos ${ }^{3}$
}

Instituto Federal de Educação, Ciência e Tecnologia Baiano - Campus Catu (Brasil) Rua Barão de Camaçari, 118, Centro, 48110-000, Catu, Bahia, Brasil Tel: +55 71 36417901;

1 e-mail: adriana.arnaut@catu.ifbaiano.edu.br; ${ }^{2}$ e-mail: antonio.prado@catu.ifbaiano.edu.br; ${ }^{3}$ e-mail: christian.santos@catu.ifbaiano.edu.br

\section{RESUMO}

Este trabalho apresenta comparativos de resultados de coordenadas obtidas por dois métodos de posicionamento GNSS: Posicionamento por Ponto Preciso (PPP) e estático pós-processado. Os resultados mostram que, a depender da finalidade do levantamento, tanto pontos obtidos pelo método GNSS do PPP com receptores geodésicos (L1/L2), como os obtidos pelo método estático pós-processado em redes topográficas locais com receptores topográficos (L1), podem ser usados na obtenção de pontos de controle para levantamento topográfico convencional.

\section{PALAVRAS-CHAVE}

Rede topográfica, GNSS, Posicionamento, PPP. 


\section{A COMPARATIVE ANALYSIS BETWEEN GNSS METHOD GNSS OF PPP AND CONVENTIONAL GEODESIC METHODS}

\section{ABSTRACT}

This article presents the results of the comparison between the coordinates yielded by two GNSS positioning methods: Precise Point Positioning (PPP) and static post process. The results show that, depending on the purpose of the surveying, the points yielded by GNSS of PPP methods with geodesic receivers (L1/L2) and the points yielded by the static post process in topographic local network with topographic receivers (L1), can be used in order to yield points of control for a conventional topographic surveying.

\section{KEYWORDS}

Topographic Network, GNSS, Positioning, PPP.

\section{INTRODUÇÃO}

Uma rede ou um conjunto de pontos referenciados geograficamente em um mesmo sistema de referência é de fundamental importância para o desenvolvimento de atividades em diversos campos de trabalho e finalidades, nas áreas de construção civil, meio ambiente, geoprocessamento, mapeamento, levantamento topográfico, dentre outros. Este conjunto de pontos pode ser obtido através de métodos e técnicas de levantamentos que, ao longo do tempo, passaram por diversas evoluções. Desde que foram disponibilizados para uso civil, os sistemas de posicionamento e navegação por satélites vêm contribuindo muito nos levantamentos geodésicos e topográficos, possibilitando de forma mais rápida e precisa a obtenção de coordenadas geodésicas de pontos na superfície terrestre.

O presente trabalho foi motivado pelos resultados de levantamentos em atividades de aulas do curso Técnico em Agrimensura, Campus Catu, do Instituto Federal de Educação, Ciência e Tecnologia Baiano (IF Baiano), ao estudar a obtenção de pontos por método de Posicionamento por Ponto Preciso (PPP) e posicionamento estático pós-processado por meio da tecnologia de Sistema de Navegação Global por Satélites (GNSS). Este trabalho tem como objetivo mostrar uma comparação entre coordenadas obtidas pelos métodos de posicionamento em estudo, verificando qual destes apresenta melhor resultado para uso em levantamentos topográficos planimétricos. 


\section{APRESENTAÇÃo DO TEMA}

O PPP é um método de posicionamento GNSS que requer fundamentalmente o uso de efemérides e correções dos relógios dos satélites, ambos com alta precisão (MONICO, 2007, 314). Para tanto, o ponto deve ser rastreado por um receptor GPS de simples ou dupla frequência durante algumas horas. Já no posicionamento relativo estático, os receptores GPS/ GNSS utilizados devem rastrear, simultaneamente, os satélites visíveis por um período de tempo de 20 minutos até várias horas. Pode-se trabalhar com as observáveis de pseudodistância ou fase da onda portadora, a depender do comprimento da linha base, pois conforme o IBGE (2008, 10, apud MONICO 2000) "levantamentos realizados em linhas de base com comprimento inferior a $10 \mathrm{~km}$, cujos receptores estejam estacionados em locais onde não haja ocorrência de obstrução e sob condições ionosféricas favoráveis, 20 minutos são suficientes para se conseguir solução das ambiguidades com receptores de simples frequência”.

\section{METODOLOGIA UTILIZADA}

Os levantamentos GNSS do Campus foram realizados conforme especificações técnicas do Instituto Brasileiro de Geografia e Estatística (IBGE). No rastreio dos pontos visando o processamento através do método PPP, cada ponto foi ocupado por um receptor geodésico (L1/L2), da marca Magellan e modelo PROMARK 500, durante um tempo de rastreio de 3 horas. Os dados foram processados utilizando o serviço PPP do IBGE através do sítio http://www.ppp.ibge.gov.br/ppp.html. Quanto ao rastreio dos pontos pelo método estático pós-processado para implantação da rede geodésica, utilizou-se um receptor geodésico PROMARK 500, instalado em um ponto base identificado como GDS-M-0002, implantado pela Petróleo Brasileiro S.A. (PETROBRAS), e, ao mesmo tempo, outros dois pontos da rede foram ocupados por receptores GPS topográficos (L1), da marca Magellan e modelo PROMARK 3. O rastreio em cada ponto durou em média 30 minutos pelo fato do comprimento da linha base ser menor que $10 \mathrm{~km}$. Buscou-se a permuta dos receptores, ocupando todos os pontos de forma que em cada ponto fossem rastreados os mesmos satélites du- 
rante o mesmo período de tempo, configurando assim a rede geodésica conforme a Figura 1. Quanto ao processamento e ajustamento dos dados obtidos para a finalidade da rede, utilizou-se o software GNSS Solutions.

Para avaliar a qualidade dos pontos PPP e da rede geodésica, buscou-se comparar os resultados de ângulos e distâncias obtidos pelas coordenadas, a partir de formulações da geometria euclidiana e do problema inverso de Puissant, com observações de ângulos e distâncias obtidos por métodos convencionais da topografia.

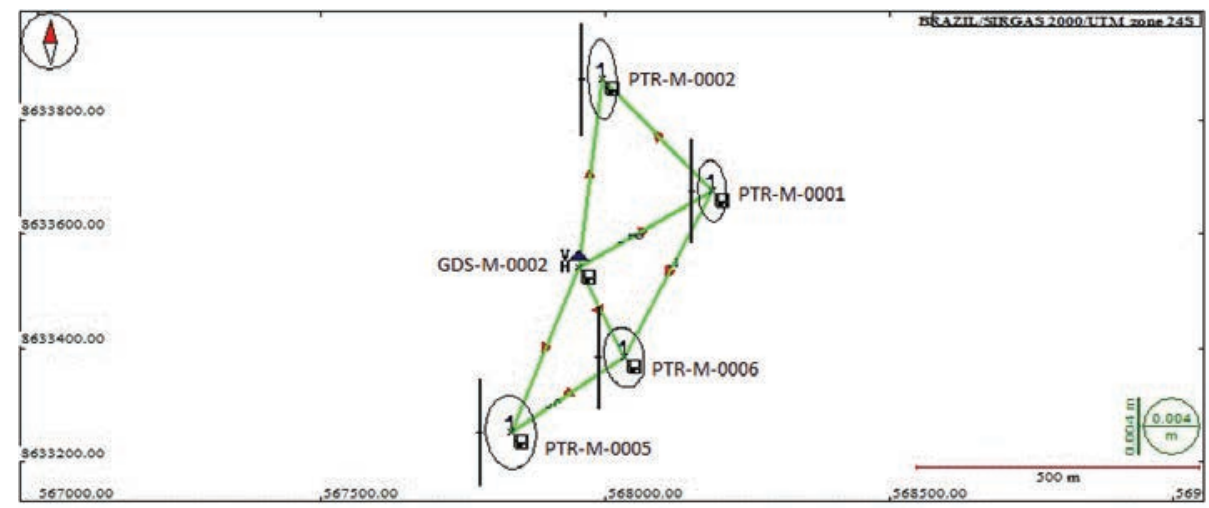

Figura 1 - Rede geodésica do IF Baiano Campus Catu Vista obtida do software GNSS Solutions

O método utilizado para obtenção dos ângulos na topografia convencional foi o das direções em posição direta (PD) e posição inversa (PI), por meio de uma Estação Total da marca Ruide modelo RTS821. Para comparar estas observações angulares e lineares medidas pelos equipamentos topográficos com as obtidas pelos métodos GNSS, as coordenadas planas UTM (Universal Transversa de Mercator) no sistema geodésico SIRGAS 2000 foram transformadas para coordenadas topográficas locais utilizando o software DataGeosis Office, versão Demo.

\section{APRESEnTAÇÃo dos ReSUltados}

A Tabela 1 apresenta as coordenadas planas UTM e as coordenadas planas topográficas locais (PTL) obtidas a partir dos métodos GNSS. 
Tabela 1 - Coordenadas planas UTM e PTL

\begin{tabular}{|c|c|c|c|c|c|c|}
\hline \multirow{2}{*}{ MARCO } & \multicolumn{2}{|c|}{$\begin{array}{c}\text { ESTÁTICO } \\
\text { PÓS-PROCESSADO }\end{array}$} & \multicolumn{2}{|c|}{ PPP } & \multicolumn{2}{|c|}{ DIFERENÇAS } \\
\hline & E (m) & $\mathbf{N}(\mathbf{m})$ & $\mathbf{E}(\mathbf{m})$ & $N(m)$ & $\mathrm{DE}(\mathrm{m})$ & $\mathrm{DN}(\mathrm{m})$ \\
\hline PTR-M-0002 & 567994,114 & 8633870,556 & 567994,220 & 8633870,564 & 0,110 & 0,010 \\
\hline PTR-M-0001 & 568186,908 & 8633676,520 & 568186,991 & 8633676,542 & 0,080 & 0,020 \\
\hline PTR-M-0006 & 568032,399 & 8633383,509 & 568032,489 & 8633383,520 & 0,090 & 0,010 \\
\hline \multirow[t]{2}{*}{ PTR-M-0005 } & 567834,257 & 8633253,120 & 567834,300 & 8633253,118 & 0,040 & 0,002 \\
\hline & $\mathbf{X}(\mathrm{m})$ & $\mathbf{Y}(\mathrm{m})$ & $\mathbf{X}(\mathbf{m})$ & $\mathbf{Y}(\mathrm{m})$ & DX (m) & DY (m) \\
\hline PTR-M-0002 & 150000,000 & 250000,000 & 150000,000 & 250000,000 & 0,000 & 0,000 \\
\hline PTR-M-0001 & 150193,343 & 249806,319 & 150193,320 & 249806,332 & 0,020 & 0,010 \\
\hline PTR-M-0006 & 150039,442 & 249512,801 & 150039,427 & 249512,803 & 0,020 & 0,002 \\
\hline PTR-M-0005 & 149841,507 & 249381,884 & 149841,444 & 249381,873 & 0,060 & 0,010 \\
\hline $\begin{array}{r}\text { Obs } \\
-2 \\
\text { ve }\end{array}$ & $\begin{array}{l}\text { ções: SGR } \\
\text { o PTR-M-0 } \\
\text { ue foi cons }\end{array}$ & $\begin{array}{l}\text { IRGAS } 200 \\
2 \text {, as difere } \\
\text { erado o pla }\end{array}$ & $\begin{array}{l}\text { Meridiano } \\
\text { s nas coor } \\
\text { topográfic }\end{array}$ & $\begin{array}{l}\text { tral }-39^{\circ} \mathrm{W} \\
\text { adas foram } \\
\text { ngente a es }\end{array}$ & $\begin{array}{l}\text { duso U } \\
\text { dlas un }\end{array}$ & \\
\hline
\end{tabular}

Observa-se nas coordenadas PTL uma maior variação em $\mathrm{X}$ na ordem de 0,060 $\mathrm{m}$ enquanto que em Y a maior diferença foi de 0,010 m.

A Tabela 2 apresenta os ângulos e distâncias obtidos matematicamente em função das coordenadas planas UTM e os ângulos e distâncias obtidos pela Estação Total em campo.

Tabela 2 - Valores de ângulos e distâncias

\begin{tabular}{|c|c|c|c|}
\hline \multirow{2}{*}{ MÉTODO } & OBSERVAÇÃo & M-0006/M-0001/M-0002 & M-0005/M-0006/M-0001 \\
\hline \multirow{2}{*}{$\begin{array}{c}\text { Estático Pós- } \\
\text { processado }\end{array}$} & Ângulo & $107^{\circ} 22^{\prime} 50^{\prime \prime}$ & $151^{\circ} 09^{\prime} 02^{\prime \prime}$ \\
\cline { 2 - 4 } & Distância & $273,667 \mathrm{~m}$ & $331,419 \mathrm{~m}$ \\
\hline \multirow{2}{*}{ PPP } & Ângulo & $107^{\circ} 23^{\prime} 03^{\prime \prime}$ & $151^{\circ} 08^{\prime} 41^{\prime}$ \\
\cline { 2 - 4 } & Distância & $273,642 \mathrm{~m}$ & $331,425 \mathrm{~m}$ \\
\hline \multirow{2}{*}{ Estação Total } & Ângulo & $107^{\circ} 22^{\prime} 47^{\prime \prime}$ & $151^{\circ} 08^{\prime} 52^{\prime \prime}$ \\
\cline { 2 - 4 } & Distância & $273,628 \mathrm{~m}$ & $331,374 \mathrm{~m}$ \\
\hline
\end{tabular}

\section{DisCuSSÃo DOS RESULTADOS}

Comparando os dados na Tabela 2 referentes aos três métodos, pode-se observar que os valores obtidos pelo método de posicionamento GNSS estático pós-processado em rede, aproximaram-se dos resultados 
obtidos pela Estação Total, principalmente nas observações angulares. Cabe ressaltar que, pela finalidade do equipamento, para os resultados apresentados levando em consideração o método de posicionamento e as características utilizadas, os receptores GPS de uma frequência apresentaram resultados aceitáveis para fins de levantamentos topográficos. Nas distâncias, por exemplo, observa-se que ambos os métodos de posicionamento obtiveram variação máxima na ordem de 0,050 m o que confirma o uso em diversos tipos de trabalhos topográficos.

\section{CONCLUSÃo}

É de fundamental importância o georreferenciamento de pontos para uso como base/referência nos levantamentos topográficos. A precisão destes pontos deve atender as normas vigentes no País, bem como à finalidade do trabalho que será executado. Pôde-se observar neste trabalho que as coordenadas PTL de bases curtas obtidos com o método estático pós-processado em rede com receptor GPS de uma frequência atendem consideravelmente aos levantamentos topográficos convencionais e que o mesmo pôde ser observado com as coordenadas PTL obtidas em função do método GNSS do PPP, porém com resultados um pouco menos favoráveis no quesito ângulos. Assim, a depender da finalidade do levantamento, tanto a obtenção de pontos por método GNSS do PPP quanto o uso do método estático pós-processado em redes obtidas com receptores topográficos, pode ser usado para pontos de controle planimétricos na topográfica convencional.

\section{BIBLIOGRAFIA}

Instituto Brasileiro de Geografia e Estatística. IBGE (2008) - Recomendações para Levantamentos Relativos Estáticos - GPS. Disponível online no endereço url: ftp://geoftp.ibge.gov.br/documentos/geodesia/pdf/recom_gps_internet. pdf (acedido em 13 Janeiro, 2014).

MONICO, João Francisco Galera (2007) - Posicionamento pelo GNSS - Descrição, fundamentos e aplicações. Editora UNESP, $2^{\mathrm{a}}$ ed., São Paulo, 480 p. 
Série Documentos

Imprensa da Universidade de Coimbra

Coimbra University Press

2015

- U M

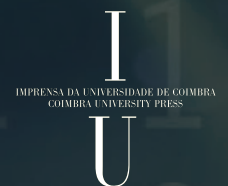

